\title{
Raging at imaginary Don-Quixotes: a reply to Giraud and Weintraub
}

\author{
DAVID TYFIELD \\ Institute for Advanced Studies, Lancaster University
}

In my article 'The impossibility of finitism: from SSK to ESK?' (Tyfield 2008), I argued that the sociology of scientific knowledge (SSK) is an important, indeed necessary, precursor of an economics of scientific knowledge (ESK), opening the way for the empirical exploration of the impact of economic factors on the production of scientific knowledge. Without SSK's arguments for the irreducible social-situatedness of science, such an ESK would be precluded, as explaining the development of scientific knowledge would be the preserve of an 'internalist' philosophy of science. SSK is thus an invaluable and indispensable contribution to our understanding of the actual scientific process.

I also argued, however, that SSK has some very serious philosophical problems. Most of the literature focuses on the problem of reflexivity. I focused, though, on a problem that I argued is more profound but that has received much less attention, namely 'meaning finitism'. This philosophical position has been increasingly emphasized by SSK, particularly of the Edinburgh School, as its primary philosophical basis. I argued that meaning finitism completely undermines the project of SSK because its explicit pronouncements contradict its necessary conditions of intelligibility, so that it is intelligible only if it is false.

Finally, having repudiated both the anti-SSK 'rationalist' philosophy of science and the anti-philosophical meaning finitism of SSK, I argued that a transcendental analysis of the necessary conditions of intelligibility of meaning-making (including in the scientific process) offers a way out of this problem. Were SSK (and ESK) to embrace this transcendental philosophical analysis, however, it would be recast as an (immanently) critical endeavour, capable of the empirical examination of science (at which it is good) without constantly having to fight rearguard 
philosophical actions to preserve its own capacity for reasoned judgement (at which it is not good).

I have opened this rejoinder to Giraud and Weintraub's (2009) response to my paper by restating my argument briefly because I hope this shows how far their characterization of my paper is from what it does in fact argue. Giraud and Weintraub's response makes absolutely no mention of the transcendental analysis at the heart of my argument. Nor does it discuss the critique of meaning finitism at any length. Discussion of the two central issues to my paper is thus simply absent. Instead, they caricature my position (Giraud and Weintraub 2009, 53) as simply an all-too-familiar anti-SSK tirade of a recidivist philosophy of science; indeed one with a lineage from time immemorial (pp. 57-58). The hugely positive assessment of SSK and the repudiation of such 'internalist' philosophy of science in my paper are also thereby simply disregarded.

Nevertheless, I am grateful to Giraud and Weintraub for giving me this opportunity to clarify my position. I expect what follows is also unlikely to convince them, but it will at least serve to repudiate some important misreadings of my argument. In only a brief article such as this there is insufficient space to deal exhaustively with all the points raised by their reply. I will therefore proceed directly to the substantive issues their reply raises. I must first, however, briefly rebut a number of the more shrill of their accusations, though others will have to go unanswered.

A major plank of their argument is that I either misquote or do not reference at all central claims of my characterization of SSK. The implication is that the SSK criticized is a straw man, indeed "simply strange" or "absurd" (Giraud and Weintraub 2009, 55-56)—despite my explicit care to appraise SSK on its own terms (Tyfield 2008, 71-72). There are several issues here. First, I must reply regarding the specific allegation of 'sententious' misquotation regarding the 'baby throwing itself out with its own bathwater' analogy (Giraud and Weintraub 2009, 57; referring to Tyfield 2008, 73). As my use of this phrase makes perfectly clear, I am not quoting Hands directly (the phrase is not in quotation marks) but I reference him since the phrase per se is his not mine, albeit in a different context. Lest there be any doubt, here again is what I say: "Hands $(1994,95)$ uses the phrase, but I note that he is not referring directly to SSK when he does so" (Tyfield 2008, 73, footnote 16). Furthermore, the footnote continues with references to others who 
have used similar phraseology about SSK itself, so that my use of it is indeed familiar and defensible.

Secondly, that I do not offer references in some sentences regarding characterizations or criticisms of SSK is simply beside the point. On the one hand, my characterization is heavily referenced, so there is plenty of evidence presented for the views attributed to SSK (see inter alia Barnes and Bloor 1982; Barnes, et al. 1996; Bloor 1981, 1991, 1997, 1998, 2004), including specific examples of directly contradictory pronouncements from leading SSK proponents (e.g., Tyfield 2008, 76, footnote 19). Arguing that they are absent in some specific sentences is simply to make selective use of the whole paper. On the other, their demand seems to rule out any paraphrasing for the sake of subsequent philosophical appraisal. Yet it is SSK's argument that I am assessing and I see no reason why I should be limited to use its own words to do so.

Ironically, much of Giraud and Weintraub's comments are themselves based on misreadings and non-sequiturs, which seem to evidence a determination to find fault rather than a will to engage. Amongst the most striking examples is the claim that "Tyfield is aware of his illegitimate move" (Giraud and Weintraub 2009, 55) regarding a shift from the 'pragmatist' theory of truth supposedly employed by SSK to the 'anti-pragmatist' one allegedly employed in my argument. In fact, I do not accept this move is illegitimate, as I discuss below. But the evidence adduced for this alleged mea culpa is a footnote clarifying the different, and potentially confusing, use of the term 'extension' by philosophers and sociologists, respectively as the set of things covered by a class-term and the act of developing or extending that set. It is hard to see the connection here with the point Giraud and Weintraub are making.

Similarly, dismissing my characterization of SSK as simply absurd also depends upon misquotation and wilful refusal to understand what is being said. For instance, following the quotation of a paragraph regarding the factors involved in the development of science, they suggest that the quotation attributes to SSK some outlandish views about epistemological issues regarding the interaction of evidence and theory (Giraud and Weintraub 2009, 55). Yet the paragraph clearly refers to SSK's (legitimate) repudiation of the belief of 'philosophers of science' that the development of science can be fully explained by an internalist account, i.e., an entirely orthogonal issue, as the sentence immediately following (which they choose not to quote) makes clear: "SSK's solution 
is that social interests are the relevant determining factor and thus social science can explain the development of science more generally (Barnes 1982, 35; Barnes, et al. 1996, 29)" (Tyfield 2008, 67).

Let us turn now to the substantive points in their reply, of which three are particularly important. These are: (1) that my argument is based primarily on the impatience of a "philosopher of science" (Giraud and Weintraub 2009, 58) with SSK; (2) that this is illegitimate as SSK must be appraised according to its own pragmatist criteria, and thus not doing so presents a straw man that merely finds in SSK faults of its own making; and (3) that the argument as a whole evidences a familiar lack of engagement with SSK's sociological work, rather than philosophical argument, as can be seen in my demand for the illegitimate importation of an evaluative or normative dimension to its descriptive, empirical programme. I will deal with each of these in turn.

First, let me restate that I think SSK, in both its philosophical pronouncements and sociological work, offers exceptionally important and cogent insights into understanding of the development of scientific knowledge. For instance, I whole-heartedly endorse the argument that explaining why scientific controversies pass cannot be conducted on the presumption that the 'true' position prevailed, but depends (overwhelmingly, perhaps) on the entirely contingent consonance of particular positions and social context and the sheer fading into obscurity of those who oppose the emergent dominant paradigm and their findings (e.g., Barnes, et al. 1996, 35). I also gladly concede to Giraud and Weintraub that scientific knowledge is accepted by particular scientists on the basis of pragmatic, socio-historically situated judgement and so must be empirically studied as such.

Nevertheless, from within SSK thus, I remain critical of it on two counts. First, its philosophical reflections undermine its important sociological programme and, moreover, do so needlessly. Giraud and Weintraub seem to claim that one must be implacably opposed to SSK to see this as the case. Yet this is manifestly contradicted by the heated debate within SSK regarding self-refutation and the implications of it (e.g., Pickering 1992). Their insinuation that to be critical of SSK is to be anti-SSK ex ante is thus totally bogus. Secondly, I argue that rectifying SSK's needless and needlessly distracting philosophical aporia also thereby alters the sociological project slightly, by admitting the normative dimension, always already there, of its subject matter. 
These two criticisms, in fact, map almost directly onto Giraud and Weintraub's second and third substantive criticisms, namely the illegitimacy of appraising SSK with non-pragmatist criteria (to use their terminology), and the illegitimacy of demanding a critical edge to SSK respectively. In turning to these issues, though, I will focus specifically on the issue of meaning finitism, not pragmatism as Giraud and Weintraub do, for three reasons: first, my original paper focuses on the former not the latter as the central philosophical position of SSK, pace Giraud and Weintraub's suggestion to the contrary $(2009,52-53)$ that it is my argument that finitism is central to SSK, rather than SSK's own claim that it is so; ${ }^{1}$ secondly, shifting to the latter would thus demand a fuller treatment than can be provided in the limited space of a reply; and finally, I would argue in any case that the issues raised by Giraud and Weintraub are subsidiary problems to that of meaning finitism and so can be dealt with substantially the same form of reasoning.

Taking each issue in turn, I readily concede that SSK (or indeed any position) cannot be legitimately appraised except from within, i.e., by way of immanent critique. Otherwise analysis does indeed lead to the problems Giraud and Weintraub indicate regarding straw man fallacies and finding problems that are the result of the evaluating framework itself, not the position being appraised. However, this does not mean that SSK can only be philosophically assessed using pragmatist criteria, for immanent critique also includes comparison of what a position states and what it necessarily presupposes. This is precisely the nature of my argument regarding SSK's problems with meaning finitism; i.e., it involves the assessment of meaning finitism not according to some ex ante, externally imposed criteria, as Giraud and Weintraub argue, but using concepts that it itself necessarily uses as a condition of its intelligibility.

This form of argument, examining necessary conditions of intelligibility, however, leads to a two-stage critique. The first stage highlights the contradiction between explicit pronouncements and implicit presuppositions, leading to the conclusion that the former must be false. In the case of meaning finitism, as I show in my paper, this leads to the conclusion that this position is intelligible only if it is false because it presupposes intensional, and not merely extensional, meaning-meaning that, both, enables and constrains its future usewhile explicitly denying such. But insofar as the latter (e.g.,

\footnotetext{
${ }^{1}$ See, for instance, Barnes, et al. 1996; Bloor 1998; Bloor 2004.
} 
intensionality) is derived by transcendental argument, starting from the pragmatic, socio-historically situated premises demanded of a legitimately non-foundationalist SSK, then SSK no longer needs to choose between the false dilemma of a non-foundationalist extensionalism (use determines meaning) and an ex ante intensionalism (meaning determines use). Rather the open-ended non-logicallydetermined and eminently socio-pragmatic matter of extensionality of meaning is seen to be a mutual condition of intelligibility of intensionality. And intensionality is understood here as the possibility of a proposition or term to have a determinate meaning in a given sociohistorical context and not a fixed, complete and perfect essence.

The conclusion of my argument is thus that the concepts repudiated by SSK (in this case intensionality) are both fundamentally ungrounded, as SSK correctly argues, and necessary or inescapable, as it consistently denies, hence its intractable philosophical problems. SSK often comes tantalizingly close to this conclusion itself, only to refute it at the last minute. For instance, Barnes, Bloor, and Henry $(1996,85)$ state that "there would appear to be no escaping a realist orientation to the world we live in and the ubiquitous conventions of the realist mode of speech". This is incredibly close to my argument, but this conclusion is cast in terms of a particularly intractable and lamentable social 'convention', and one SSK should be on its guard to repudiate. Yet the fact that such 'realist' talk cannot be avoided is because it is a necessary condition of intelligibility of discourse itself, not because of social convention identifiable a posteriori. In short, SSK need only admit this problem to be an inescapable philosophical one, and it could preserve its non-foundationalism or pragmatism while forsaking its forlorn attempt to do without that on which it necessarily depends.

This takes us to the final point, namely the suggestion that my paper overlooks empirical work in SSK and is thus harmfully incomplete in its conclusions regarding what can and cannot be done by ESK and SSK. In particular, it is argued that I would aim to have a SSK/ESK that can uncover the deleterious effects of commerce on a pristine "virginal" science (Giraud and Weintraub 2009, 58), while actual SSK work, such as Shapin's (2008), does engage with these issues but yields completely different insights.

Certainly, there is little discussion in my paper of the details of this literature, if only due to constraints of space and the paper's primary focus on a philosophical argument. It is also the case that I would like 
an ESK that can explore the impact of economic social factors on the production of scientific knowledge, and in ways that go beyond the insights yielded by existing SSK. This is not, however, premised upon an ex ante presumption (borne of a 'rationalist' philosophy of science) that 'money' is 'bad' for science-what Mirowski and Van Horn (2005) have called 'Mertonian Toryism'-but the acknowledgement that the goals of commerce and of science, manifest in all their complexity in concrete situations, may often be in conflict; which is hardly controversial. Hence, as I put it in my article, an ESK "should be able to offer a critique of how and where the imposition of economic imperatives on scientific research has a detrimental effect on the 'scientific knowledge' thereby produced" (Tyfield 2008, 82, emphasis added). And, perhaps I should add as its flipside: how and where it has no such detrimental effect.

On this conception, however, Giraud and Weintraub's citation of Shapin's (2008) new book as the kind of work that shows what SSK can do and its incompatibility with the programme I am proposing-to my supposed "annoyance" (Giraud and Weintraub 2009, 58) - can be seen to be quite wrong, for in many respects this is exactly what Shapin's book does. Indeed, Giraud and Weintraub may be pleased (or perhaps disappointed) to know that I read this book (as other work in the field) with great interest. I thoroughly endorse Shapin's statement that "later modern entrepreneurial science is sometimes celebrated and sometimes condemned. [...] But [...] rarely is it described in much detail" (Shapin 2008, 229, original emphasis) and that this forms a good basis for a programme of social scientific work. Similarly, I fully accept Shapin's insistence upon the need to explore the ongoing shift in boundaries between commerce and science in detail, as a social phenomenon that is not fully amenable to "unitary, simple or tidy" linear accounts (Shapin 2008, 13)-from mythical pasts to idealized present-and that such research should be based upon the presumption that "it is better to see the relationship between virtue and the pursuit of knowledge [as one that] has been reconfigured than to assume it has been dispensed with" (Shapin 2008, 17).

However, I do not accept Shapin's explicit protestations (Shapin 2008, 18, 313)-even while I accept them to be perfectly genuine-that his work is thus purely descriptive and without any normative conclusions. Certainly, normative commitments cannot legitimately structure the empirical work ex ante, but supposedly neutral description of that which is always already value-laden is impossible and will in 
general serve merely to naturalize the status quo. The only way to avoid this, and thus to keep open the relevant normative questions, is to engage with them explicitly. In this respect, Shapin's investigation can be seen to be radically incomplete. He asks effectively: is individual scientific virtue equally prevalent in both academic and industrial settings? Yet the more important question, and the one that keeps open the associated normative issues, is: how has commercializing science changed the science done and which or whose interests does this privilege? Shapin's question describes the problem, while the latter situates it, and both are necessary.

Against Giraud and Weintraub's $(2009,57)$ suggestion that my position is one of a stout defender of the moral purity of science against the relativist barbarians, the transformed and critical SSK I am proposing explores science as a highly contested, social and value-laden process-both after and before its current commercialization. In this context, though, SSK has the role of identifying the social forces impacting on the production of science and holding these up for open, participatory debate.

Furthermore, this is not to deny that the complexity of the empirical reality renders such normative judgement difficult. But it does not make it impossible, unless one is tacitly assuming that normative judgement must itself always be sweeping and monochrome, rather than detailed and nuanced. Indeed, the conclusion of such investigation is both a wholesome disillusionment with grand black-and-white normative judgements, as per reasonable pragmatist scepticism, and detailed understanding of the complex interweaving of potentially contradictory normative trends and effects based on acknowledgement of the inescapability of normative judgement on social phenomena, for all its difficulty. It is the latter that SSK's descriptivist posture systematically occludes.

To be sure, this is a more politically engaged form of SSK, but I am by no means alone in arguing for this from within science and technology studies (STS) more broadly, where there are increasing calls for STS to engage with political issues, including evaluation of the effects of commercialisation of science on the 'knowledge' produced (e.g., a forthcoming special edition of Social Studies of Science). Furthermore, with both grand normative conclusions and denial of normative responsibility ruled out, the conclusion of such enquiry is not crude political slogans but the deepening of the embodied capacity for 
normative judgement, i.e., a form of 'moral/political education' with potentially significant social repercussions.

In short, in our mutual affirmation of Hess's comment that the "dismissive caricatures and distortions of a huge volume of theory and research" (Hess 1997, 1; as quoted on Giraud and Weintraub 2009, 57) is potentially even more troubling than some of SSK's more relativist excesses, Giraud and Weintraub's and my position are much closer than they evidently care to admit. Nevertheless, their dismissive refusal to engage with the latter, and arguments about it, does little to further the debate. Indeed, such hostile repudiation of even SSK-sympathetic criticism can only deepen the philosophical problems that beset SSK by encouraging the continued refusal even to admit their existence. It is also effectively to block any possibility of moving beyond the sterile and heated debate about the problem of reflexivity, to which Giraud and Weintraub seem committed to drag us back. Conversely, I would argue that the transcendental analysis and critical project I have proposed could lead beyond the long-standing 'dialogue of the deaf' between SSK and philosophy of science to their mutual improvement and benefit. Readers will decide for themselves which path seems more attractive.

\section{REFERENCES}

Barnes, S. Barry, and David Bloor. 1982. Relativism, rationalism and the sociology of knowledge. In Rationality and relativism, eds. Martin Hollis, and Steven Lukes. Oxford: Blackwell, 21-47.

Barnes, S. Barry, David Bloor, and John Henry. 1996. Sociology of scientific knowledge. London: Athlone Press; Chicago: University of Chicago Press.

Bloor, David. 1981. The strengths of the strong programme. Philosophy of the Social Sciences, 11: 199-213.

Bloor, David. 1991. Knowledge and social imagery (2nd edition). London and Boston: Routledge and Kegan Paul.

Bloor, David. 1997. Wittgenstein, rules and institutions. London and New York: Routledge.

Bloor, David. 1998. Changing axes: response to Mermin. Social Studies of Science, 28 (4): 624-635.

Bloor, David. 2004. Institutions and rule-scepticism: a reply to Martin Kusch. Social Studies of Science, 34 (4): 593-601.

Giraud, Yann, and E. Roy Weintraub. 2009. Tilting at imaginary windmills: a comment on Tyfield. Erasmus Journal for Philosophy and Economics, 2 (1): 52-59. http://ejpe.org/pdf/2-1-art-3.pdf

Hands, D. Wade. 1994. The sociology of scientific knowledge: some thoughts on the possibilities. In New directions in economic methodology, ed. Roger Backhouse. London: Routledge, 75-106. 
Hess, David. 1997. Science studies: an advanced introduction. New York and London: New York University Press.

Mirowski, P., and R. Van Horn. 2005. The contract research organization and the commercialization of science. Social Studies of Science, 35 (4): 503-548.

Pickering, Andrew (ed). 1992. Science as practice and culture, Chicago: University of Chicago Press.

Shapin, Steven. 2008. The scientific life: a moral history of a late modern vocation, Chicago: University of Chicago Press.

Tyfield, David. 2008. The impossibility of finitism: from SSK to ESK? Erasmus Journal for Philosophy and Economics, 1 (1): 61-86. http://ejpe.org/pdf/1-1-art-3.pdf

David Tyfield is a research associate at the Institute for Advanced Studies, Lancaster University. His research is on the (global) political economy and philosophy of science and innovation, with a particular focus on climate change and the life sciences.

Contact e-mail: <d.tyfield@lancaster.ac.uk> 